\section{Psychological consequences of traumatic injury ${ }^{\dagger}$}

\author{
CHRISTOPHER S. THOMAS
}

Whiplash injuries commonly occur in road traffic accidents, although early descriptions of railway spine following rail accidents would appear to be similar (Trimble, 1981). Initial acute symptoms include neck pain, restricted mobility in the cervical spine, headache, pain in the thoracic spine, radiating pain, paraesthesiae and/or weakness in the arms or legs (Spitzer et al, 1995). These somatic symptoms often are accompanied by psychological symptoms such as initial 'shock', a 'dazed' feeling, anxiety, anger, depression, difficulty concentrating, insomnia, lassitude, loss of libido, altered appetite and weight and, in some cases, feelings of helplessness, horror, despair and reliving experiences (Mayou \& Radanov, 1996).

Most people who suffer whiplash injuries make a complete recovery but a significant proportion suffers enduring somatic and/or psychological symptoms. Symptom complexes persisting for more than 6 months sometimes have been referred to as 'late whiplash syndromes' (Balla, 1982). The aetiology of the persistent symptomatology usually is multifactorial. There is a subtle interplay between organic factors causing physical injury and functional factors such as personality type, pre-existing psychiatric disease or vulnerability, substance misuse, gender, employment status, legal framework, unrelated but coincidental life events and related life events such as ill health retirement, conscious and unconscious exaggeration and the effects of litigation.

The severity of any associated psychiatric disorder is variable. Some may have none or only a mild psychological disturbance, which may or may not be admitted to or, alternatively, identified by their family doctor. The majority of patients with mild to moderate psychological disorders usually are treated in primary

†See pp. 44I-448, this issue. care. Psychiatrists working in the secondary sector therefore may see a small but very skewed population who suffer from severe psychiatric disorder in association with a whiplash injury.

Conversely, psychiatrists acting as expert witnesses for the purpose of some form of medico-legal assessment may see a significant proportion of individuals with mild to moderate psychological disorders as well as those with more severe disorders. These conditions include acute stress reaction, adjustment disorder, phobia, post-traumatic stress disorder, anxiety disorder, depressive disorder, substance misuse, pain syndrome and rarely psychosis. In more severe cases where there has been an accompanying head injury with loss of consciousness, similar disorders may occur but post-traumatic stress disorders appear to be less frequent (Mayou et al, 1993). Personality changes and cognitive impairment may occur following contre-coup and penetrating head injuries (Lishman, 1987).

Pain syndromes often have an initial organic basis, which may be caused by the acceleration/deceleration force occurring at the time of the accident. There is a moderate amount of evidence that this pain may cause psychological distress (Lee et al, 1993; Wallis et al, 1997; Olivegren et al, 1999). The hypothesis that the psychological distress associated with whiplash injury is secondary to pain is supported by Wallis et al's (1997) study of 24 patients who received radiofrequency neurotomy for their whiplash symptoms. In that study, those patients who experienced relief of their pain symptoms also exhibited resolution of their pre-operative psychological distress.

However, it is acknowledged also that the relationship between a subject's mood and pain symptomatology is dynamic, with pain symptoms being aggravated or maintained by persistent psychological symptomatology such as heightened level of arousal, anxiety or depression of mood. In such situations, pain symptomatology may persist long after the organic pathology has subsided. These psychological symptoms, which augment or magnify the experience of pain, sometimes are referred to as 'functional overlay' by medical colleagues. This term has unfortunate pejorative overtones and may be used in a more general sense when there are inconsistencies on physical examination, such as the demonstration of non-organic medical signs (Waddell et al, 1980). These nonorganic signs, referred to by Main \& Waddell (1998) as 'behavioural' signs, are not by themselves a test of credibility or veracity. However, where associated psychological features are absent and/or there are inconsistencies in the patient's history, there may be allegations that the patient is exaggerating or malingering. In a single clinical consultation or medicolegal assessment it may be difficult to identify confidently the true explanation for such phenomena and the matter may be determined only by a judge in court.

Kennedy (1946), when describing psychological symptoms associated with accidents, cynically stated: 'a compensation neurosis is a state of mind, born out of fear, kept alive by avarice, stimulated by lawyers, and cured by a verdict'. In one series of 50 consecutive medico-legal assessments in which pain was a significant symptom, $98 \%$ of the patients were considered to be exaggerating their disability (Kay \& Morris-Jones, 1998). Cassidy et al (2000) considered that if financial compensation is determined by the continued presence of pain and suffering, then such an insurance system might promote illness and disability. In support of this hypothesis, they found a decreased incidence and improved prognosis of whiplash injury when the tort compensation system was changed to a no-fault system in Saskatchewan, Canada, in 1995.

The outcomes of accident-related syndromes vary, with some studies showing significant improvements in somatic and mental symptoms at 2 years (Olivegren et $a l$, 1999) or when litigation had been completed (Miller, 1961), whereas other studies demonstrate persistent difficulties at follow-up (Mendelson, 1995; Kelly \& Smith, 1981; Tarsh \& Royston, 1985; Squires et al, 1996; Blanchard et al, 1998). Some of the variation in outcomes between the different studies may relate to factors such as small sample sizes, highly 
selected populations, lack of a control group, differences in mode of referral and the orientation and attitude of the assessing specialist. Most of the subjects assessed by Miller (1961) and Kay \& Morris-Jones (1998) were referred by defendants' solicitors or insurance companies. In contrast, almost all the litigants in the studies of Tarsh \& Royston (1985) and Mendelson (1995) were seen at the behest of the claimants' solicitors.

Mayou \& Bryant (2001) addressed some of these potential biases in a study of consecutive attendees at an Oxford accident and emergency department. They found that just less than one-third had significant psychiatric sequelae 1 year after a road traffic accident and that seeking compensation was associated with worse physical, psychological and social outcomes, although the direction of the latter association was not clear because the claimants usually had suffered more severe injury and loss. These authors now examine the relationship between whiplash injury and psychiatric disorder in a controlled study derived from the same cohort of patients (Mayou \& Bryant, 2002, this issue). There are a number of interesting findings, not least of which is the observation that claiming compensation at 3 months was associated with pain at 1 year. If this finding is independent of the severity of injury and is replicated in other studies, then this further emphasises the potentially harmful effect of litigation upon an individual's suffering and level of functioning.

\section{ACKNOWLEDGEMENT}

I thank Dr George Hay for helpful comments on an earlier draft of this paper.

CHRISTOPHER S. THOMAS, FRCPsych, University Hospital of South Manchester, Manchester M23 9LT, UK

(First received 8 October 200I, final revision 17 December 200I, accepted 17 December 200I)

\section{DECLARATION OF INTEREST}

None.

\section{REFERENCES}

Balla, J. (1982) The late whiplash syndrome: a study of an illness in Australia and Singapore. Culture, Medicine and Psychiatry, 6, 191-210.

Blanchard, E. B., Hickling, E. J., Taylor, A. E., et al (1998) Effects of litigation settlements on posttraumatic stress symptoms in motor vehicle accident victims. Journal of Traumatic Stress, II, 337-354.

\section{Cassidy, J. D., Carroll, L. J., Cote, P., et al (2000)}

Effect of eliminating compensation for pain and suffering on the outcome of insurance claims for whiplash injury. New England Journal of Medicine, 342, II79-1186.

Kay, N. R. M. \& Morris-Jones, H. (1998) Pain clinic management of medico-legal litigants. Injury, $\mathbf{2 9}$, 305-308.

Kelly, R. \& Smith, B. N. (198I) Post-traumatic syndrome: another myth discredited. Journal of the Royal Society of Medicine, 74, 275-277.

Kennedy, F. (1946) The mind of the injured worker: its effect on disability periods. Compensation Medicine, $\mathbf{I}$ 19-21.

\section{Lee, J., Giles, K. \& Drummond, P. D. (1993)}

Psychological disturbances and an exaggerated response to pain in patients with whiplash injury. Journal of Psychosomatic Research, 37, 105-110.

Lishman, A. (1987) Organic Psychiatry. The Psychological Consequences of Cerebral Disorder. Oxford: Blackwell Scientific.

Main, C. J. \& Waddell, G. (1998) Spine update behavioural responses to examination. A reappraisal of the interpretation of 'non organic signs'. Spine, 23, 2367-237I.

Mayou, R., Bryant, B. \& Duthie, R. (1993) Psychiatric consequences of road traffic accidents. BMJ, 307, $647-651$.
— \& Radanov, B. P. (1996) Whiplash neck injury. Journal of Psychosomatic Medicine, 40, 46I-474.

— \& Bryant, B. (2001) Outcome in consecutive emergency department attenders following a road traffic accident. British journal of Psychiatry, 179, 528-534.

— \& - (2002) Psychiatry of whiplash neck injury. British Journal of Psychiatry, 180, 44I-448.

Mendelson, G. (1995) 'Compensation neurosis' revisited: outcome studies of the effects of litigation. Journal of Psychosomatic Research, 39, 695-706.

Miller, H. (1961) Accident neurosis. BMJ, i. 919-925; 992-998.

Olivegren, H., Jerkvall, N., Hagstrom, Y., et al (1999) The long term prognosis of whiplash-associated disorders (WAD). European Spine Journal, 8, 366-370.

Spitzer, W. O., Skovron, M. L., Salmi, L. R., et al (1995) Scientific monograph of the Quebec Task Force on Whiplash-Associated Disorders: redefining 'whiplash' and its management. Spine, 20 (suppl. 8), IS-73S.

Squires, B., Gargan, M. F. \& Bannister, G. C. (1996) Soft-tissue injuries of the cervical spine, 15 year followup. Journal of Bone and Joint Surgery, 78-B, 955-957.

Tarsh, M. J. \& Royston, C. (1985) A follow-up study of accident neurosis. British journal of Psychiatry, 146, 18-25.

Trimble, M. R. (198I) Post Traumatic Neurosis, from Railway Spine to the Whiplash. Chichester: John Wiley \& Sons.

Waddell, G., McCulloch, J. A., Kummel, E., et a (1980) Non-organic physical signs in low back pain. Spine, 5, 117-125.

Wallis, B. J., Lord, S. M. \& Bogduk, N. (1997) Resolution of psychological distress of whiplash patients following treatment by radiofrequency neurotomy: a randomised, double-blind, placebo controlled trial. Pain, 73, $15-22$. 